\title{
Effect of Microstructure on Surface Roughening in Stretch Forming of Steel Sheets
}

\author{
Masahiro KUBO, ${ }^{1,2) *}$ Yoshiaki NAKAZAWA, ${ }^{3)}$ Takayuki HAMA $^{2)}$ and Hirohiko TAKUDA ${ }^{2)}$ \\ 1) Research \& Development Bureau, Nippon Steel \& Sumitomo Metal Corporation, Amagasaki, Hyogo, $660-0891$ Japan. \\ 2) Graduate School of Energy Science, Kyoto University, Kyoto, 606-8501 Japan \\ 3) Research \& Development Bureau, Nippon Steel \& Sumitomo Metal Corporation, Futtu, Chiba, 293-8511 Japan.
}

(Received on June 5, 2017; accepted on July 14, 2017)

\begin{abstract}
Surface quality is an important requirement in outer automobile panels, and to obtain products with an excellent surface quality the development of surface roughening during press forming should be prevented. However, the influence of microstructures on surface roughening is not yet sufficiently understood, and thus it is difficult to control surface roughening during press forming. In this study, the mutual effect of the development of texture and the surface profile variation is examined in detail using two types of tests: a Marciniak type test used for surface roughening observation, and a microscopic biaxial tensile test in a vacuum chamber of scanning electron microscope. The latter test enables in-situ continuous observations of microstructure evolution under biaxial deformation, which is a typical deformation mode in press forming. Interstitial free (IF) steel sheets are used in this study because these sheets are mainly used for outer panels. Results show that surface roughening becomes large for sheets which have a larger number of crystal grains with orientations in the vicinity of $N D(001)$ due to inhomogeneous deformation derived from their lower deformation resistance. It is therefore suggested that surface quality after press forming may be further improved by reducing the number of grains with crystal orientation of ND(001) in IF steel sheets.
\end{abstract}

KEY WORDS: surface roughening; sheet metal forming; microstructure; texture; interstitial free steel; EBSD.

\section{Introduction}

In recent years, in order to meet the diversifying needs of car users, more complicated exterior designs are being used in automobile design and there is an increasing demand for outer panels with sharper streamlines. Exterior panels with sharper ridge lines are generally produced through press forming, using tools with small radii. In this press forming, so-called "surface roughening" defects are caused due to the comparatively large plastic deformation near sharp ridge lines. Surface roughening is characterized by unevenness ${ }^{1,2)}$ in mesoscopic order occurring on the sheet surface, and negatively affects the appearance of the products. Surface roughening is also characterized by waviness of comparatively long wave-lengths, in the order of 0.1 to $1.0 \mathrm{~mm}$.

To understand the mechanism of surface roughening in press forming, many studies have been conducted on aluminum and steel sheets. It has been generally reported that surface roughening linearly increases with plastic strain, ${ }^{3-22)}$ and is affected by not only press forming conditions such as the strain ratios or strain path, but also by material factors such as crystal grain size,${ }^{3-11,16-24)}$ crystal structure, ${ }^{10)}$ crystal orientation $^{19-22,25-30)}$ and texture. ${ }^{2,25,31,32)}$

\footnotetext{
* Corresponding author: E-mail: kubo.m9p.masahiro@jp.nssmc.com DOI: http://dx.doi.org/10.2355/isijinternational.ISIJINT-2017-320
}

In early studies, surface roughening was examined experimentally. Yamaguchi and Mellor ${ }^{3)}$ showed that the degree of surface roughening in an Al-killed steel sheet depended on the amount of equivalent plastic strain and the crystal grain size. Mahmudi et $a{ }^{77}{ }^{7}$ reported that the degree of surface roughening in copper sheets could also be explained in a similar way, and that surface roughening was caused by inhomogeneity of the material microstructure. Osakada et al. ${ }^{10)}$ revealed that the degree of development of surface roughening depended also on the strain state, i.e. tensile or compressive deformations, and the crystal structure, i.e. hexagonal close-packed (HCP) structure, face-centered cubic (FCC) structure or body centered cubic (BCC) structure. Guangnan ${ }^{15)}$ conducted studies on the development of surface roughening under uniaxial and biaxial tension using steel and aluminum sheets, and pointed out that the rotation of crystal orientation caused by plastic strain was the main factor of surface roughening. Kawai et al. ${ }^{18)}$ investigated the effect of strain ratio on the surface roughening of an aluminum sheet and presumed that the deformation of interior crystal grains from the surface to the second layer could affect the surface unevenness.

More recently, how interior crystal grains affect the development of surface roughening has also been studied using numerical simulations. Yamaguchi et al. ${ }^{19)}$ analyzed surface roughness of aluminum sheets under plane strain 
deformation and found that surface roughening was affected mainly by the crystal grains in the surface layer. Moreover, they surmised that the inhomogeneous deformation of interior crystal grains until the fourth layer from the surface affected the surface roughening. In contrast, Lee et al. ${ }^{31)}$ stated that there was no evident relationship between the crystal orientation of the surface layer and surface roughening in aluminum sheets under plane strain tension. Wu et $a l .^{27)}$ stated that interactions among interior crystal grains due to deformation affected the development of surface roughening. They analyzed the phenomena of surface roughening in aluminum sheets during biaxial tensile forming by crystal plasticity analysis, and indicated that surface roughening could be inhibited by randomizing the crystal orientation of the interior grains. Using a similar analytical method, Shi et $a l{ }^{33)}$ carried out studies on an aluminum sheet under simple bending deformation, which showed that the influence of crystal grains at sheet surface on surface roughening was dominant.

Recently many detailed studies concerning the relationship between surface roughening and superficial and interior microstructures are being carried out using crystal orientation analysis by electron backscattered diffraction pattern (EBSD) or Atomic Force Microscopy (AFM). Tong et al. ${ }^{26)}$ directly studied the relation between superficial microstructures and surface profiles via in-situ observation of uniaxial tensile tests of aluminum sheets. Kimura et al. ${ }^{30)}$ observed the surface roughening of high purity ferrite stainless steel sheets with intensive texture of (111)[112] at shrinking flange in deep drawing by EBSD. Banovic et al. ${ }^{32)}$ analyzed the relationship between the texture of aluminum sheets and the development of surface roughening under equi-biaxial tensile deformation state using a Marciniak type test, ${ }^{34)}$ and showed that in aluminum sheets the development of surface roughening occurred strongly in material with intensive texture of (220). In addition, they stated that the texture of (220) became more intensified by applying biaxial tensile deformation.

Although many studies have been carried out on surface roughening, there have been few studies for steel sheets with BCC structure compared with studies for aluminum sheets with FCC structure. Furthermore, studies for steel sheets have been limited to common carbon steel sheets. We are completely lacking in knowledge of surface roughening of steel sheets such as interstitial free (IF) steel sheets, which are mainly used for automotive outer panels. In order to overcome the problem of surface roughening in press forming of IF steel sheets, it is necessary to clarify the influences of microstructures, such as crystal grain size, texture and crystal orientation, on surface roughening.

In this study, therefore, surface roughening and the change of microstructure of IF steel sheets during biaxial tensile deformation are examined in detail using two types of tests. One is a macroscopic Marciniak type test; the other test is a microscopic biaxial tensile test in a vacuum chamber, developed by the authors ${ }^{35)}$ and which enables insitu continuous observations of sheet surface during biaxial deformation with EBSD techniques. The effect of interior microstructure on surface roughening is also discussed, based on cross sectional observation of the sheets after biaxial deformation.

\section{Experimental Procedures}

\subsection{Materials}

Table 1 shows mechanical properties of the materials used in this study. Four types of cold-rolled and annealed steel sheets with a single phase of ferrite were employed. Properties except for $r$-values are those measured in the rolling direction (RD). The $r$-values were measured at a plastic strain of 0.15 . The in-plane anisotropy of $r$-value, $\Delta r$ was calculated as follows.

$$
\Delta r=\left(r_{0}-2 \cdot r_{45}+r_{90}\right) / 2
$$

$r_{0}, r_{45}$ and $r_{90}$ are the $r$-values in $0^{\circ}, 45^{\circ}$ and $90^{\circ}$ from $\mathrm{RD}$, respectively.

The materials differ not only in strength and $r$-value as shown in Table 1, but also in grain size and texture, as shown in Fig. 1. This figure shows inverse pole figure (IPF) maps in the plane of RD and transverse direction (TD) obtained by EBSD method. The measurements were conducted at $0.1 \mathrm{~mm}$ from the surface. Materials A, B and C are IF steel sheets, which have a developed texture of $\{111\}$ in the normal direction (ND), and have differing average grain sizes, $d$, of 20, 9.3 and $16 \mu \mathrm{m}$, respectively. Material $\mathrm{D}$ is an Al-killed steel sheet which has comparatively random crystal orientations. Material D has a grain size of $15 \mu \mathrm{m}$, almost the same as material $\mathrm{C}$.

\subsection{Observation of Surface Roughening in Marciniak Type Biaxial Tension Test}

In order to examine the influences of microstructure and texture on the development of surface roughening in press forming, the change of sheet surface in Marciniak type biaxial tension test ${ }^{34)}$ was first observed.

Equi-biaxial tensile strain was applied to $300 \mathrm{~mm} \times 300$

Table 1. Mechanical properties of materials.

\begin{tabular}{cccccccccccc}
\hline \multirow{2}{*}{ Material } & $\begin{array}{c}\text { Initial thickness } \\
{[\mathrm{mm}]}\end{array}$ & $\begin{array}{c}\mathrm{YP}^{*} \\
{[\mathrm{MPa}]}\end{array}$ & $\begin{array}{c}\mathrm{TS}^{*} \\
{[\mathrm{MPa}]}\end{array}$ & $\begin{array}{c}\mathrm{u} \text {-EL* } \\
{[\%]}\end{array}$ & $\begin{array}{c}\mathrm{EL}^{*} \\
{[\%]}\end{array}$ & \multicolumn{3}{c}{$r$-value** } & \multicolumn{2}{c}{$\begin{array}{c}\text { Average } \\
r \text {-value }\end{array}$} & $\begin{array}{c}\text { In-plane } \\
\text { anisotropy } \Delta r\end{array}$ \\
\hline $\mathrm{A}$ & 0.60 & 195 & 331 & 23 & 41 & 1.9 & 2.0 & 2.4 & 2.1 & 0.21 \\
$\mathrm{~B}$ & 0.75 & 270 & 447 & 20 & 34 & 1.1 & 1.8 & 1.6 & 1.6 & -0.46 \\
$\mathrm{C}$ & 0.75 & 185 & 340 & 25 & 44 & 1.2 & 1.8 & 1.7 & 1.6 & -0.36 \\
$\mathrm{D}$ & 1.2 & 270 & 357 & 20 & 39 & 1.2 & 0.93 & 1.5 & 1.1 & 0.44 \\
\hline
\end{tabular}

* Measured in rolling $\left(0^{\circ}\right)$ direction

** Measured at uniaxial plastic strain of 0.15 


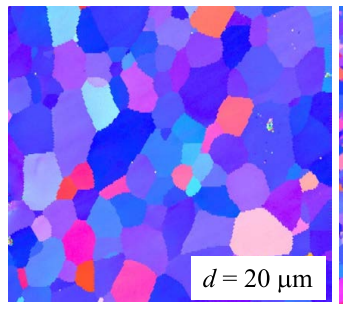

(a) Material A

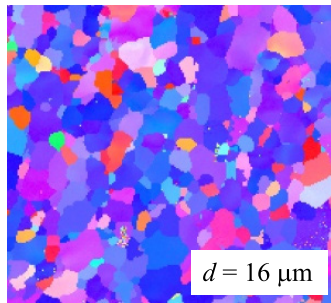

(c) Material $\mathrm{C}$

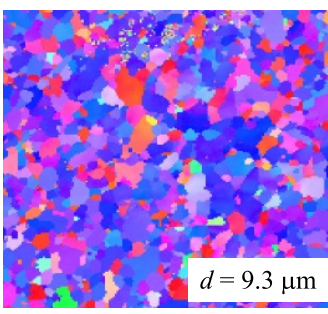

(b) Material B

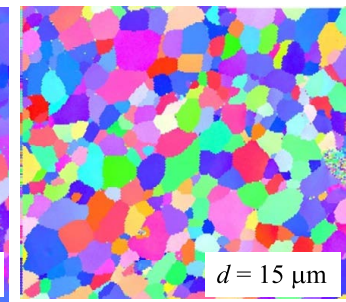

(b) Material D

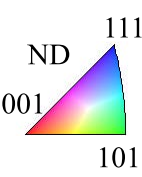

RD

$\underset{\mathrm{TD}}{\rightarrow}$

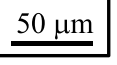

Fig. 1. Initial microstructure and texture (IPF map) of materials at $0.1 \mathrm{~mm}$ from surface ( $d=$ average grain size). (Online version in color.)

$\mathrm{mm}$ rectangular specimens using a cylindrical punch with a diameter of $100 \mathrm{~mm}$, as shown in Fig. 2. Forming speed was $10 \mathrm{~mm} / \mathrm{s}$. The plastic strain was evaluated from the changes in length of scribed patterns, with an initial grid of $2 \mathrm{~mm}$ drawn on the specimens. The strain was measured at specimen surfaces on the punch side and on the reverse side of the material. The difference in the strains on both sides was 0.002 or less at an equivalent strain of 0.50 . From this, the strain distribution was considered to be uniform in the thickness direction.

Figure 3 shows schematic view of sampling and measurement locations of specimen for microstructure analysis after Marciniak type test. The measurement of material surface was conducted on the bottom side in Fig. 2. The sheet surface was observed after stopping the test in some stages at certain punch strokes until necking occurred. After stopping the each test, each one specimen of a $25 \mathrm{~mm}$ square was cut out from the center part where the most significant surface roughening could be observed.

Macroscopic surface profiles were measured by a contact type roughness meter. Scanning was done in RD with a speed of $0.15 \mathrm{~mm} / \mathrm{s}$. Generally, the parameter of cut-off length $\lambda_{c}$ used for the arithmetical mean roughness, $R_{a}{ }^{36)}$ and the arithmetical mean waviness, $W_{a}{ }^{37)}$ is $0.8 \mathrm{~mm}$. In this study, however, in order to evaluate $W_{a}$ in a comparatively wide range, $0.25 \mathrm{~mm}$ was adopted as $\lambda_{c}$. As the evaluation length of $R_{a}$ and $W_{a}$ was $1.0 \mathrm{~mm}$, a size corresponding to approximately one fourth of that was adopted as $\lambda_{c} . R_{a}$ is used as a parameter that quantitatively represents the microscopic unevenness of surface. Surface curves with a wave length longer than $\lambda_{c}$ were denoted as waviness curves. $W_{a}$ was employed as a parameter that quantitatively represents the macroscopic waviness.

In addition, three dimensional profiles of the surface were measured by a laser microscope and a scanning electron microscope (SEM) for areas of $1.0 \mathrm{~mm}$ and $200 \mu \mathrm{m}$ square. Crystal orientations in microscopic scale were measured by SEM and EBSD method. To maintain surface unevenness as much as possible the polishing of specimens for EBSD was limited to a range of $2 \mu \mathrm{m}$ depth. ${ }^{38)}$ The electrolytic

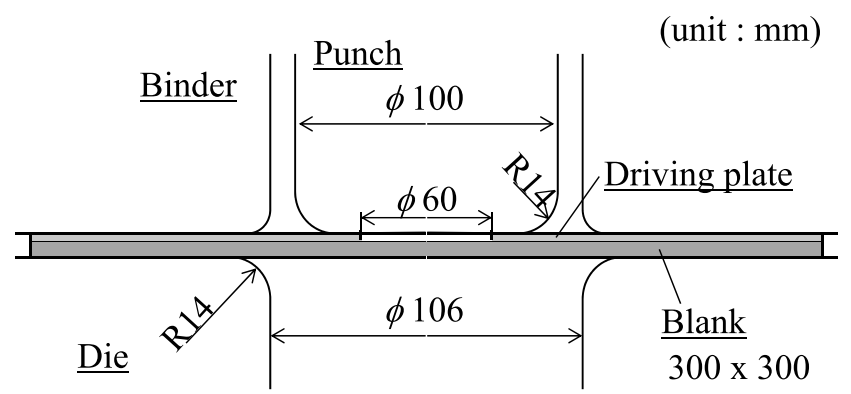

Fig. 2. Schematic of tools for Marciniak type test.

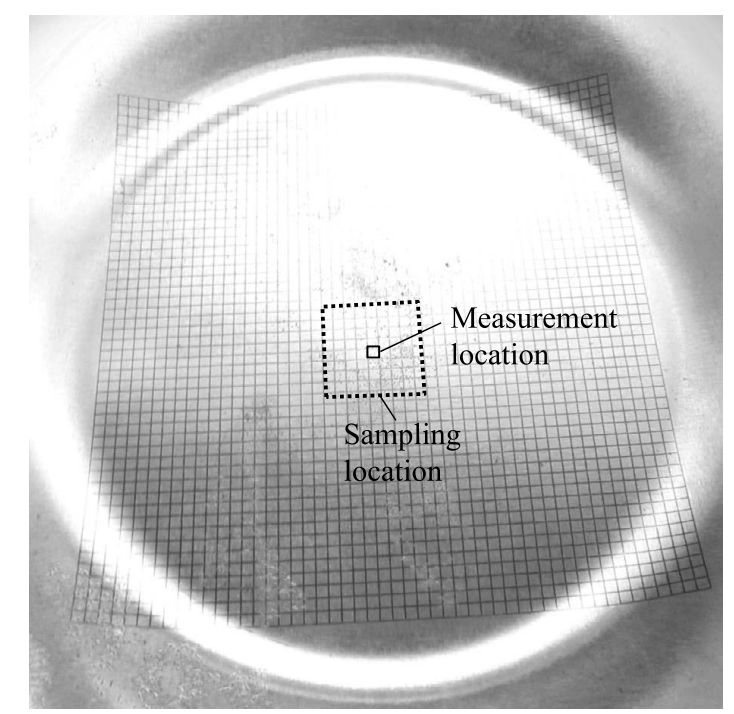

Fig. 3. Schematic view of sampling and measurement locations of specimen for microstructure analysis after Marciniak type test.

polishing time was determined by trial-and-error method using a dummy material.

\subsection{In-situ Observation of Surface Roughening in Microscopic Biaxial Tension Test}

One of the problems with the conventional observation method as described in 2.2 above is that the observation cannot be conducted continuously during deformation. In order to directly examine the relationship between macroscopic surface unevenness and microstructures, changes were observed continuously using a biaxial tensile test system equipped inside a vacuum chamber of SEM. Figure 4 shows the test system developed by the authors. For details of the experimental apparatus, refer to our previous reports. ${ }^{35,39)}$

Biaxial tensile tests were conducted at a cross head speed of $2.5 \mu \mathrm{m} / \mathrm{s}$. The equivalent strain was evaluated from the changes of length between the crystal triple points in RD and TD. In-situ observations of microstructures by SEM and EBSD were carried out within a $200 \mu \mathrm{m}$ square visual field from the central part of specimens. Crystal orientation was analyzed using OIM collection v7.2.1 (TSL Solutions) and $1 \mu \mathrm{m}$ was set as the analysis pitch of EBSD. This technique enables us to analyze surface microstructure variation without being influenced by the intermediate electrolyte polishing process.

Estimating the average strain rate from the amount of working time and substantial plastic strain, the order of the strain rate was $1.0 \times 10^{-3} \mathrm{~s}^{-1}$ in the microscopic biaxial 


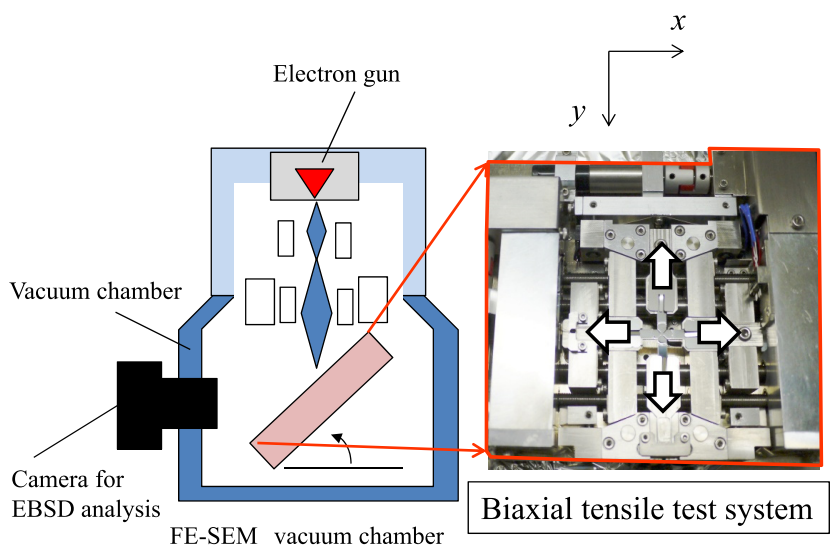

Fig. 4. Experimental apparatus for biaxial tensile test with SEMEBSD analysis. ${ }^{35,39)}$ (Online version in color.)

tension test. In a similar way, the order of the strain rate was $1.0 \times 10^{-1} \mathrm{~s}^{-1}$ in Marciniak type test. The strain rate in actual press forming is approximately $1.0 \mathrm{~s}^{-1}$. However, it was reported experimentally ${ }^{11)}$ as well as numerically ${ }^{33)}$ that the surface roughening was almost independent of the strain rate. Therefore, it is considered the result of the present study is able to be applied to actual press forming.

\section{Results}

\subsection{Development of Surface Roughening in Marciniak Type Test}

Figure 5 shows the sheet surfaces opposite to the punch side after an equivalent plastic strain, $\mathcal{E}^{p}$ eq, of 0.50 given by the equi-biaxial Marciniak type test. At the observation using the electron microscope the specimens were slightly tilted in the vertical direction so that the uneven state on the surface could be observed. Among the IF steel sheets the surface roughening of material $\mathrm{B}$ with smaller grain sizes seems to be small compared with materials $\mathrm{A}$ and $\mathrm{C}$ with larger grain sizes. Compared with material D of Al-killed steel, surface roughening of material $\mathrm{C}$ seems to be small, although the initial grain sizes are almost the same. However, the difference mentioned above cannot be precisely judged from Fig. 4.

Figure 6 shows surface profiles measured by a contact type roughness meter before the test and at punch strokes of $21 \mathrm{~mm}, 23 \mathrm{~mm}$ and $25 \mathrm{~mm}$. In the figure the equivalent plastic strain corresponding to each punch stroke is given. The vertical axis shows the relative height of surface along the measured length of $1 \mathrm{~mm}$. The selected $1 \mathrm{~mm}$ regions are the location in which the largest amplitude is observed within the length of $10 \mathrm{~mm}$. It is confirmed that the unevenness is large in materials $\mathrm{A}$ and $\mathrm{D}$ and it is recognized from this figure that the width, i.e. the interval, of unevenness is the smallest for material B with the smallest grain size.

Figure 7 shows the change of the arithmetical mean roughness, $R_{a}$, for each material during the equi-biaxial tension test. The evaluated length is $1.0 \mathrm{~mm}$ as shown in Fig. 6 . It can be seen that $R_{a}$ increases linearly with the strain for each material. This result agrees with conventional knowledge. ${ }^{3-22)}$ For IF steel sheets $\mathrm{A}, \mathrm{B}$ and $\mathrm{C}, R_{a}$ is larger for material with a larger grain size, and this result also agrees with previous studies. ${ }^{3-11,16-24)}$ However, when comparing

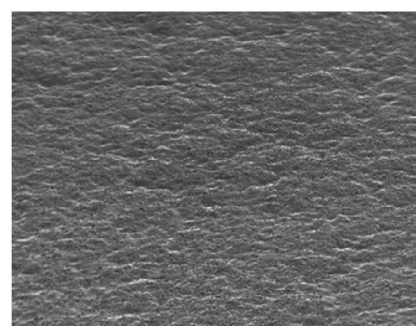

(a) Material A

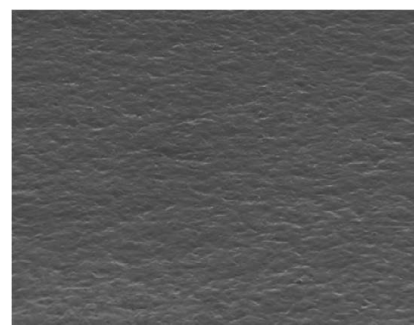

(c) Material C

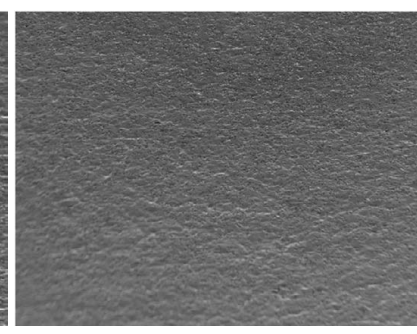

(b) Material B

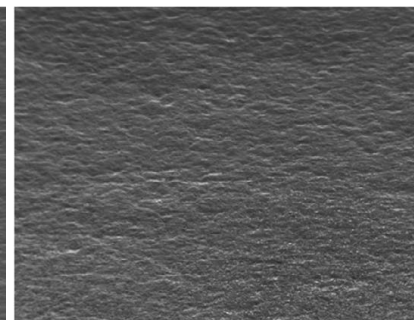

(d) Material D

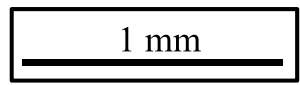

Fig. 5. Observed surface profile of specimen after Marciniak type test with equivalent plastic strain of 0.5 .

materials $\mathrm{C}$ and $\mathrm{D}, R_{a}$ of material $\mathrm{D}$ is larger even though material D has a slightly smaller grain size than material $\mathrm{C}$. This tendency is more obvious in $W_{a}$ shown in Fig. 8.

Figure 8 shows the change of the arithmetical mean waviness, $W_{a}$, for each material during equi-biaxial tension test. $W_{a}$ quantitatively represents surface roughening caused by relatively long wavelength. $W_{a}$ of materials B and C slightly increases linearly with the strain. On the other hand, $W_{a}$ of materials A and D increases strongly at a higher strain region. As a result $W_{a}$ of the material $\mathrm{D}$ becomes larger even than that of material A which has the largest grain size.

This suggests that surface roughening is related not only with grain size but also with other factors. As shown in Fig. 1 material $\mathrm{D}$ is different from materials $\mathrm{A}, \mathrm{B}$ and $\mathrm{C}$ in texture.

Figure 9 shows the evolutions of the sheet surface and the distribution of micro crystal orientation obtained by SEM and EBSD analyses. It can be confirmed again from the secondary electron images (SEI) (the left figures) that in materials $\mathrm{A}$ and $\mathrm{D}$ surface roughening becomes larger with the equivalent strain, $\varepsilon^{p}$ eq. Crystal orientations of materials $\mathrm{A}, \mathrm{B}$ and $\mathrm{C}$ before deformation incline chiefly to $\mathrm{ND}(111)$, which remains unchanged even after deformation. On the other hand, crystal orientations of material $\mathrm{D}$ are random before deformation and $\mathrm{ND}(001)$ and $\mathrm{ND}(111)$ orientations increase with deformation. Among the four materials the orientation $\mathrm{ND}(001)$ is most dominant in material $\mathrm{D}$ at large strains.

\subsection{In-situ Observation of Surface Roughening in Microscopic Biaxial Tensile Test}

As shown in the above results materials $\mathrm{C}$ and $\mathrm{D}$ differ from each other in surface roughening although their initial grain sizes are almost the same. To directly analyze the change of the microstructure in biaxial tensile deformation for materials $\mathrm{C}$ and $\mathrm{D}$ in more detail, in-situ observations were conducted by the SEM/EBSD method developed by 


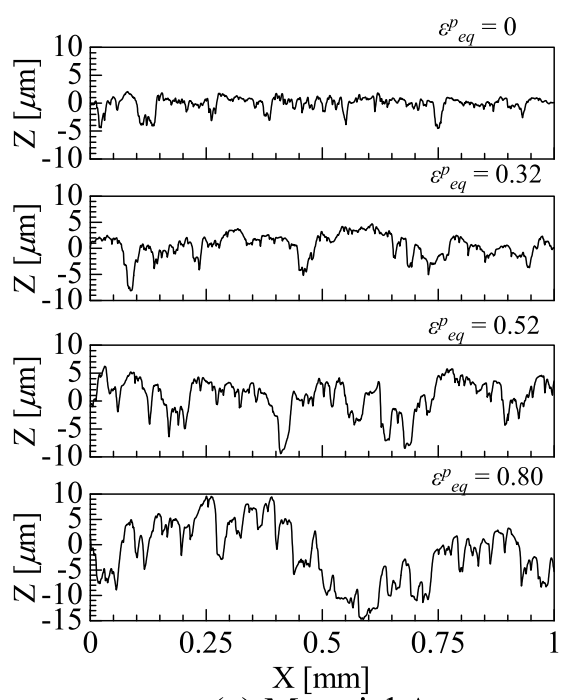

(a) Material A

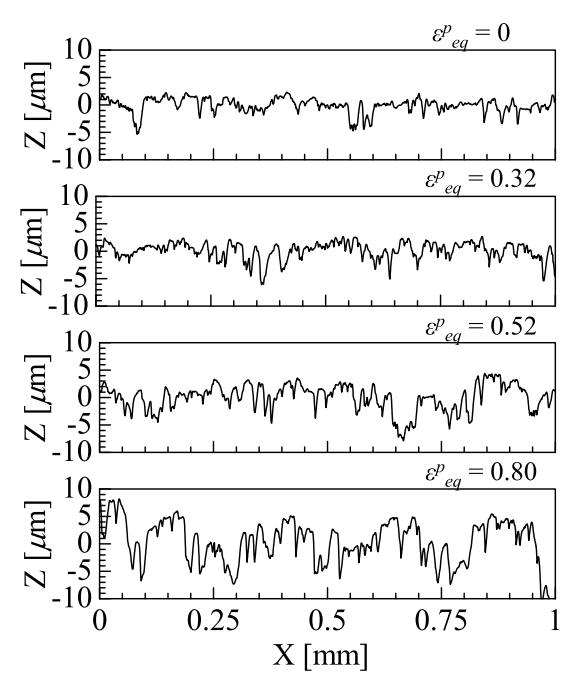

(c) Material C

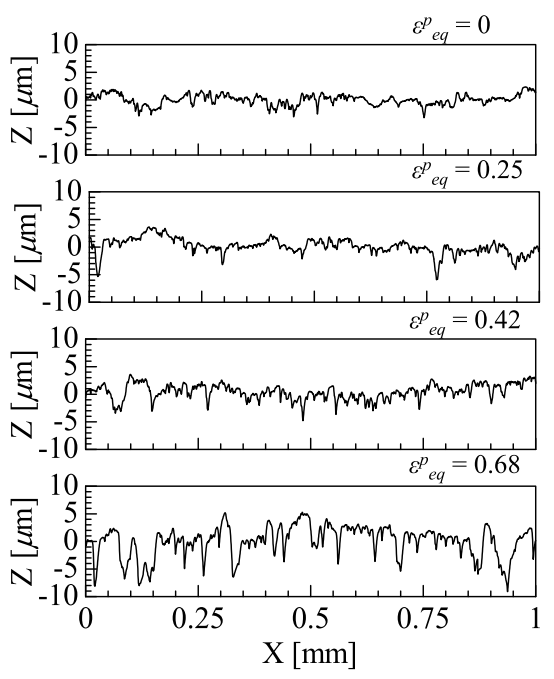

(b) Material B
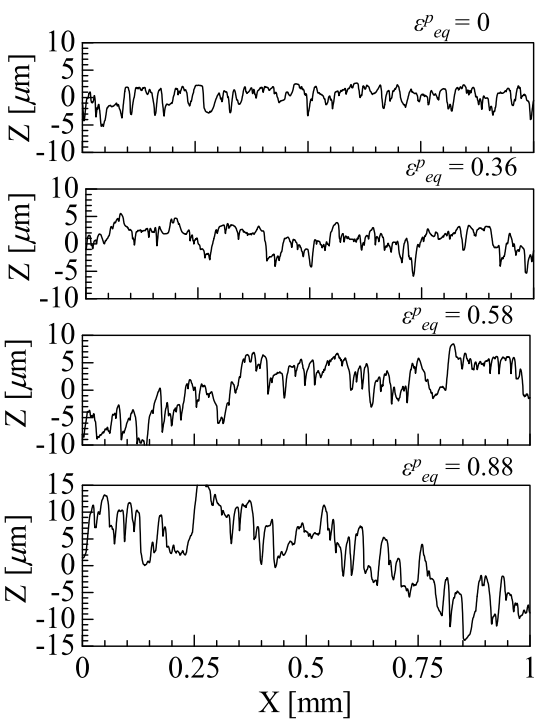

(d) Material D

Fig. 6. Magnified view of variation of surface profile during Marciniak type test.

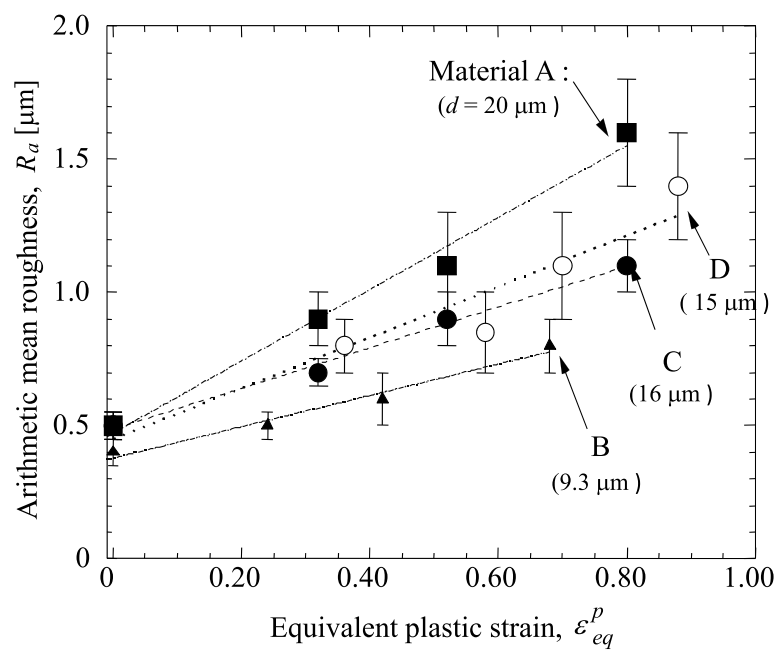

Fig. 7. Variation of surface roughness during Marciniak type test $(d=$ initial average grain size $)$.

the authors (see above 2.3).

Figures 10 and 11 show changes of microstructure at sheet surface during equi-biaxial tensile deformation for

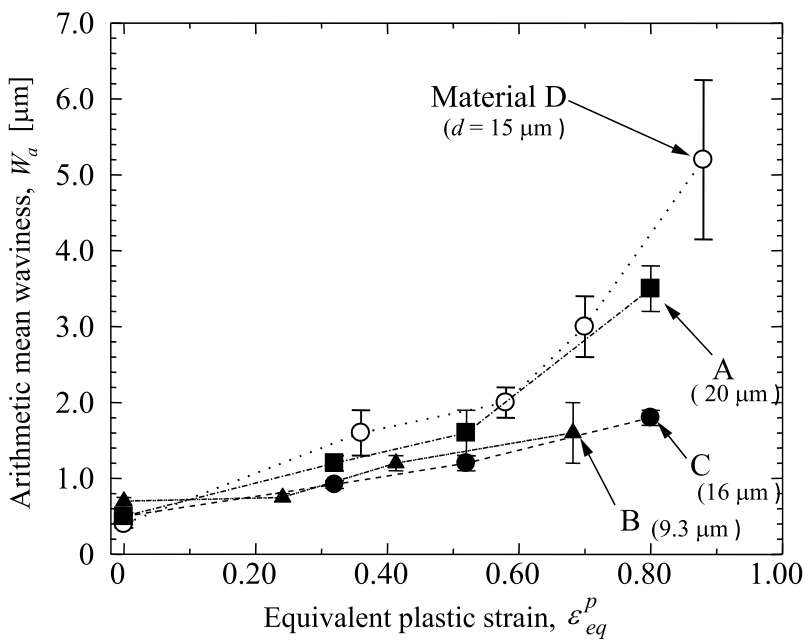

Fig. 8. Variation of surface waviness during Marciniak type test.

materials D and $\mathrm{C}$, respectively. In these figures SEI, IPF maps and Taylor factor ${ }^{40-42)}$ maps are shown. Taylor factor map is an index indicating the deformation resistance of each crystal grain. In this study the Taylor factor was 


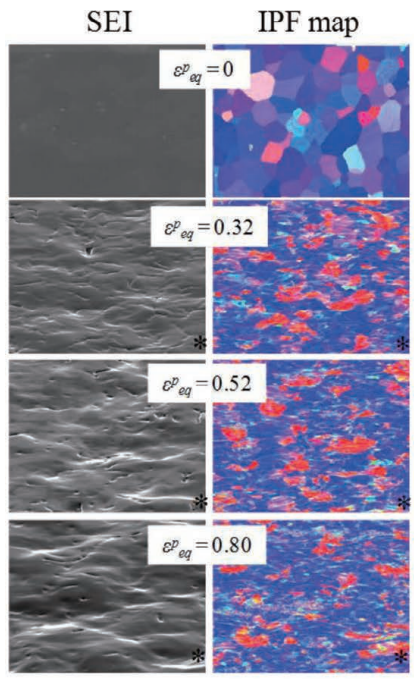

(a) Material A
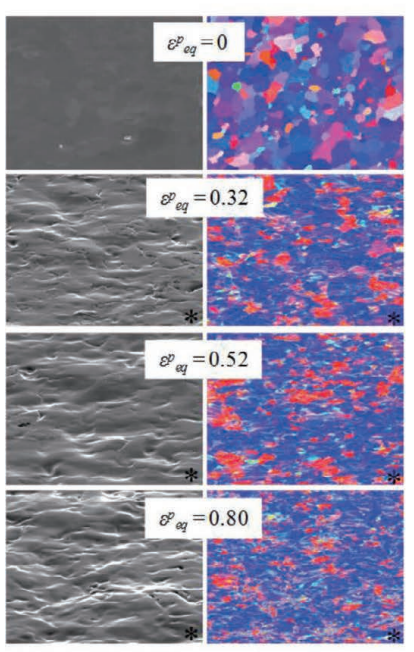

(c) Material C

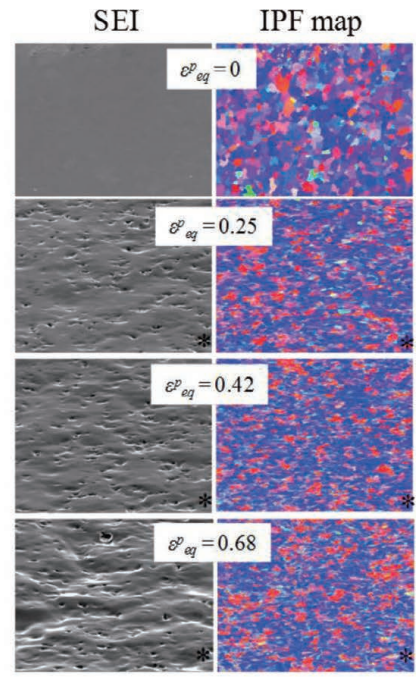

(b) MaterialB

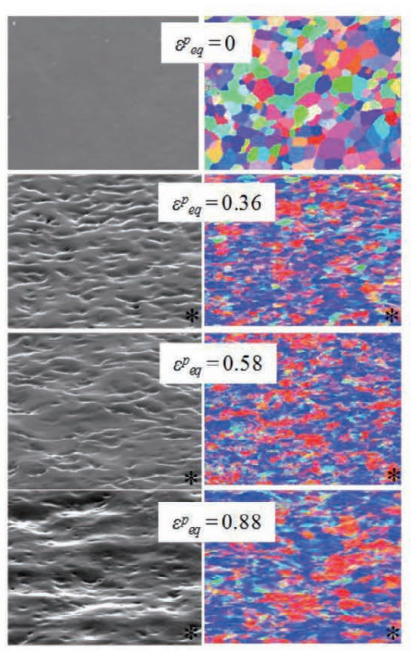

(d) MaterialD

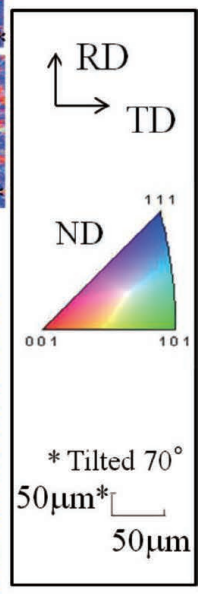

Fig. 9. Surface profile and crystal orientation in Marciniak type test.

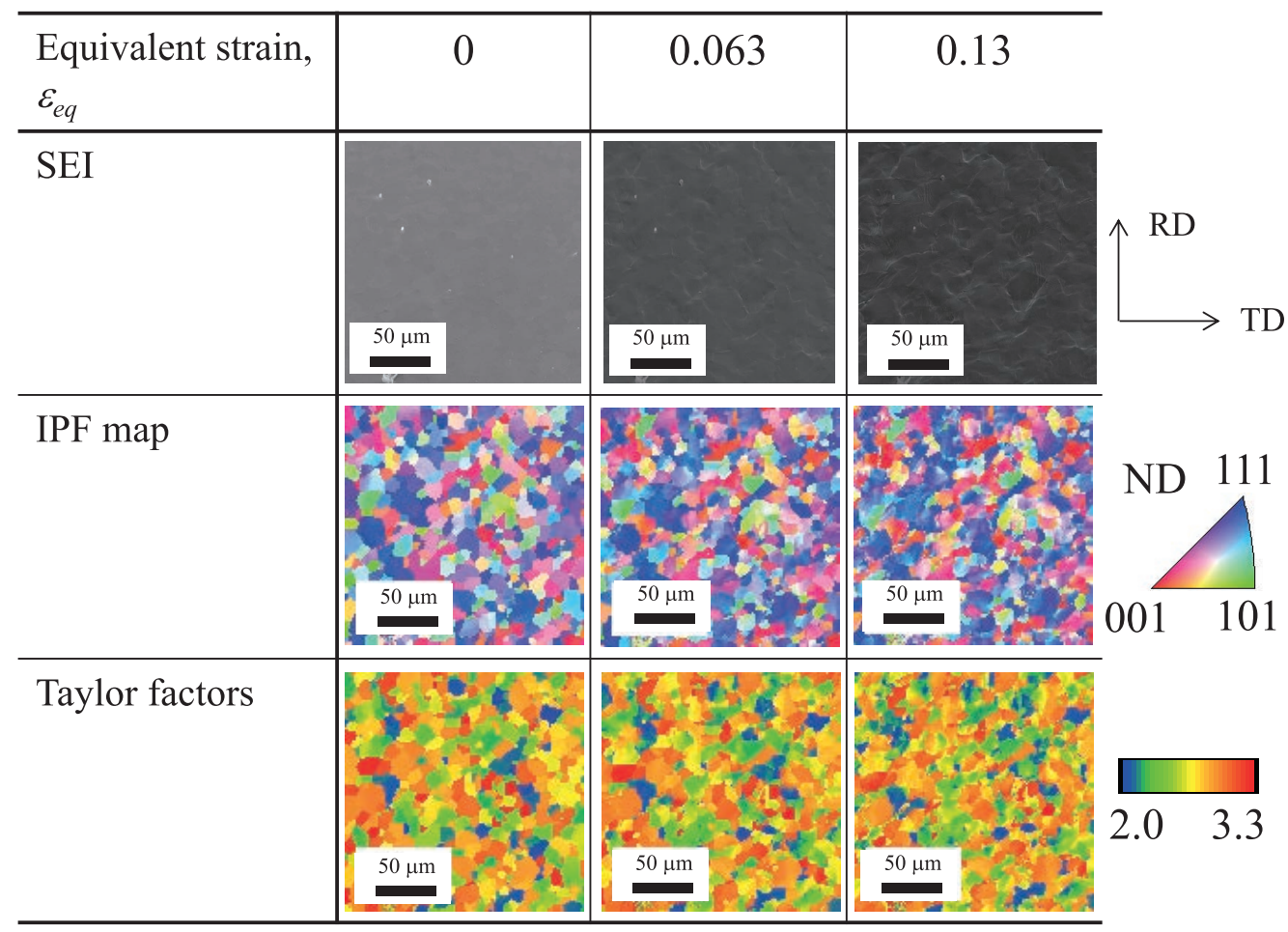

Fig. 10. SEI, IPF and Taylor factor maps of sheet surface during microscopic biaxial tensile test (Material D). 


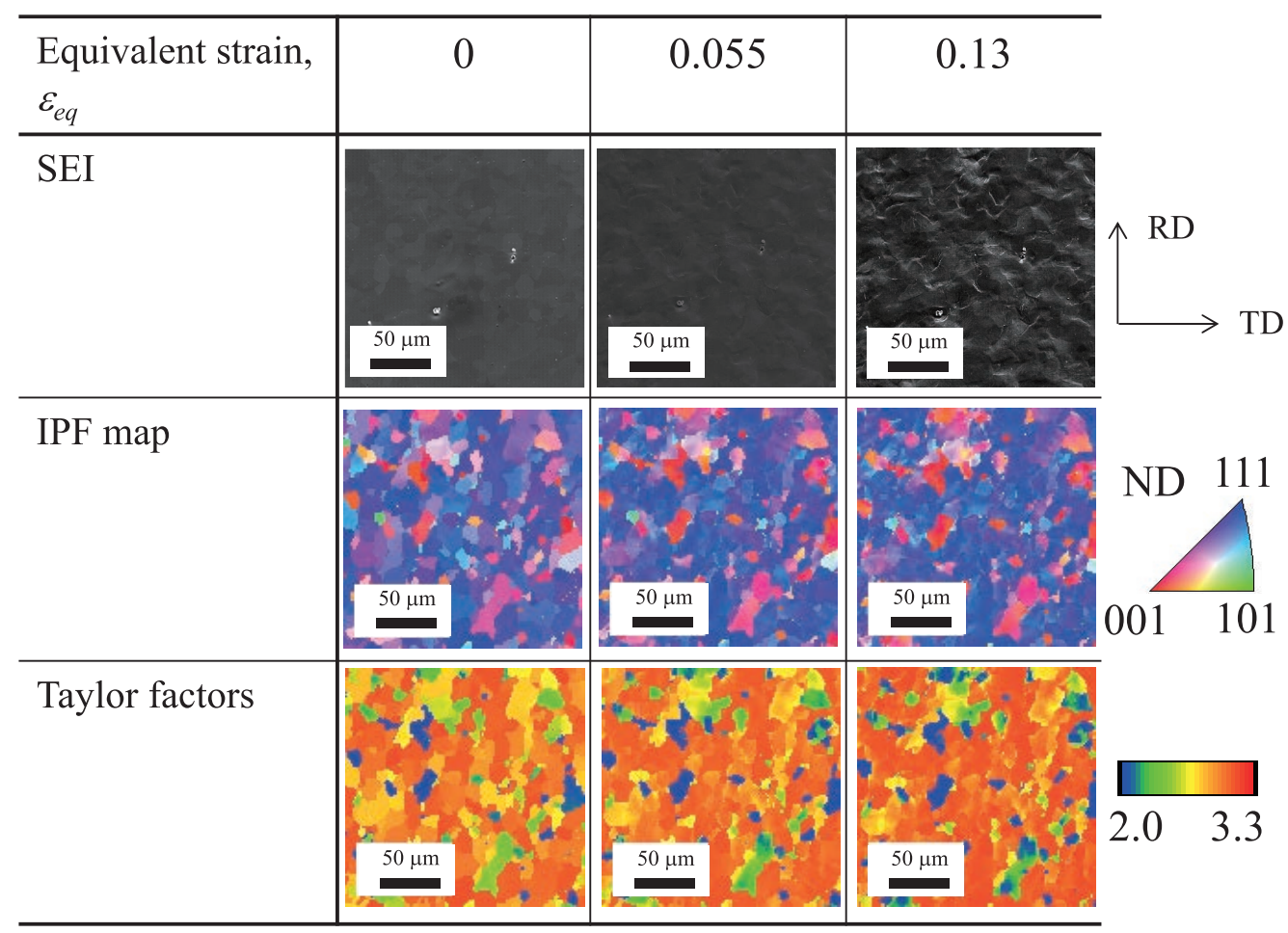

Fig. 11. SEI, IPF and Taylor factor maps of sheet surface during microscopic biaxial tensile test (Material C).

evaluated by assuming 24 slip systems of BCC structure and uniform equi-biaxial deformation with regards to the crystal orientation at each observation point, and corresponds to the reciprocal of the Schmid factor. The surface condition under equi-biaxial tension for the low strain range is highly correlated with the distribution of Taylor factors in OIM analysis, as reported in our previous study. ${ }^{35)}$

From Fig. 10, first the following characteristics of the material D are found. SEI of material D shows that a gentle, i.e. not localized, unevenness arises on the surface as plastic strain advances, which corresponds to the result shown in Fig. 6(d). From the IPF maps it is found that with increase in the plastic strain the crystal orientations become distributed even in crystal grains, and that the orientations of $\mathrm{ND}(001)$ and ND(111) develop. These results agree with the intermittent observation of microstructures shown in Fig. 9(d). The Taylor factor maps show that red-colored grains are few, while grains which have relatively low Taylor factor are distributed in a wide range. From a comparison of the IPF and Taylor factor maps in Fig. 10 it is found that the Taylor factor tends to take smaller values in the region where a group of orientations $\mathrm{ND}(001)$ exists.

From Fig. 11 the following characteristics of material $\mathrm{C}$ are found. SEI of material $\mathrm{C}$ shows the local unevenness is more pronounced in material $\mathrm{C}$ than in material $\mathrm{D}$ when the deformation proceeds. In the IPF map at the equivalent strain of 0.13 , the distribution of crystal orientations is also seen within the grains as is seen in material D. Material C has the developed texture of $\mathrm{ND}(111)$ before deformation, and the texture develops more with deformation. ${ }^{39)}$ Compared with material D, the area where crystal grains with $\mathrm{ND}(001)$ orientation exist is small. This result also agrees with the intermittent observation of microstructures shown in Fig. 9(c). In the Taylor factor maps, the large part of red color (high resistance) and the very small part of blue color (low resistance) are clearly divided. From the comparison between the IPF and Taylor factor maps in Fig. 11 it is found that material $\mathrm{C}$ has very few grains with $\mathrm{ND}(001)$ orientation and that the deformation resistance is relatively small. It is supposed that this causes the localized unevenness in material $\mathrm{C}$.

It was reported that the crystal grains with high Schmid factor (i.e. low Taylor factor) deformed on a priority basis ${ }^{43}$ ) for the low strain range. This result implies that the inhomogeneous deformations of polycrystalline grains are mainly effected by the initial crystal orientation rather than the work hardening difference in each crystal orientation for the insitu observation condition. It is presumed that under biaxial tensile deformation the crystal grains of the orientation in the vicinity of $\mathrm{ND}(001)$ have relatively low deformation resistance than the grains of the other orientations, thus facilitating inhomogeneous deformation. In case of the high strain range, however, it may be necessary to consider the effect of the work hardening difference in each crystal orientation on the inhomogeneous deformation.

\section{Discussion}

The above results have shown that the existence of grains with $\mathrm{ND}(001)$ orientation is concerned with surface roughening. Here, the direct relation between the existence of grains with $\mathrm{ND}(001)$ orientation and the surface profile is examined in detail.

Figure 12 shows the relation between the distribution of grains with $\mathrm{ND}(001)$ orientation and the surface profile after an equivalent strain of 0.13 obtained from the microscopic biaxial tension test for material C. After the measurement of IPF map the surface profile was measured by a laser microscope. The circles in the IPF map indicate the positions of grains with $\mathrm{ND}(001)$ orientation along three lines 
in $\mathrm{TD}$ and $\mathrm{RD}$, and the arrows in the right figures of surface profile indicate the corresponding positions. It can clearly be seen that the surface height is low at positions where the grains with $\mathrm{ND}(001)$ orientation exist. This may be derived from the comparatively large deformation at these positions caused by the small resistance. It is clear that the existence of grains with $\mathrm{ND}(001)$ orientation at surface layer has a great effect on surface roughening. However, there are some other concave positions along the measured lines. This reveals the possibility of the effect of interior grains.
Using the specimens after the Marciniak type test, cross sectional observations were carried out. In these results there was also the case where the effect of interior grains was found. As an example, Fig. 13 shows the IPF map of a cross section near the sheet surface, the surface profile and the distribution of Taylor factor of grains from the first to fourth layer from surface of material A after an equivalent strain of 0.5 . At the position of around $200 \mu \mathrm{m}$ on the horizontal axis, in the IPF map there are red-colored grains, i.e. with $\mathrm{ND}(001)$ orientation, in the interior layers, and these

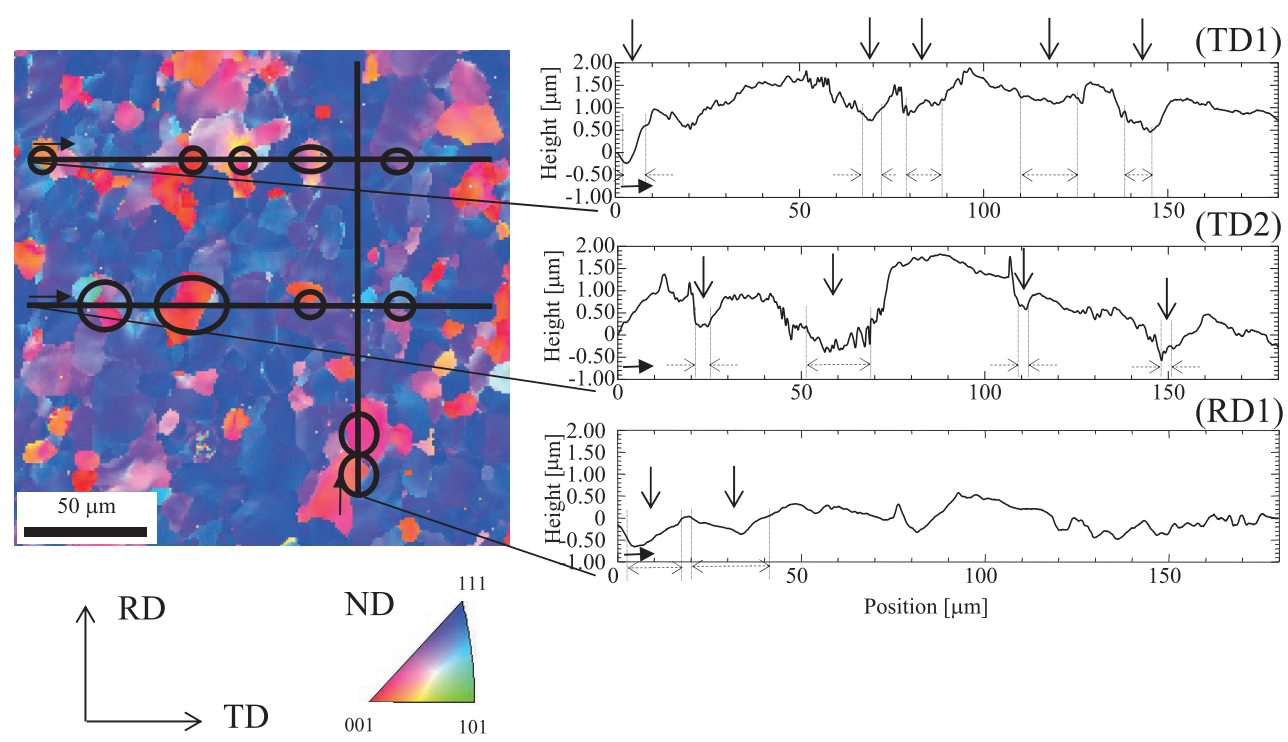

Fig. 12. IPF map of sheet surface and surface profile after microscopic biaxial tensile test for Material $\mathrm{C}$ with equivalent strain of 0.13 .

IPF map
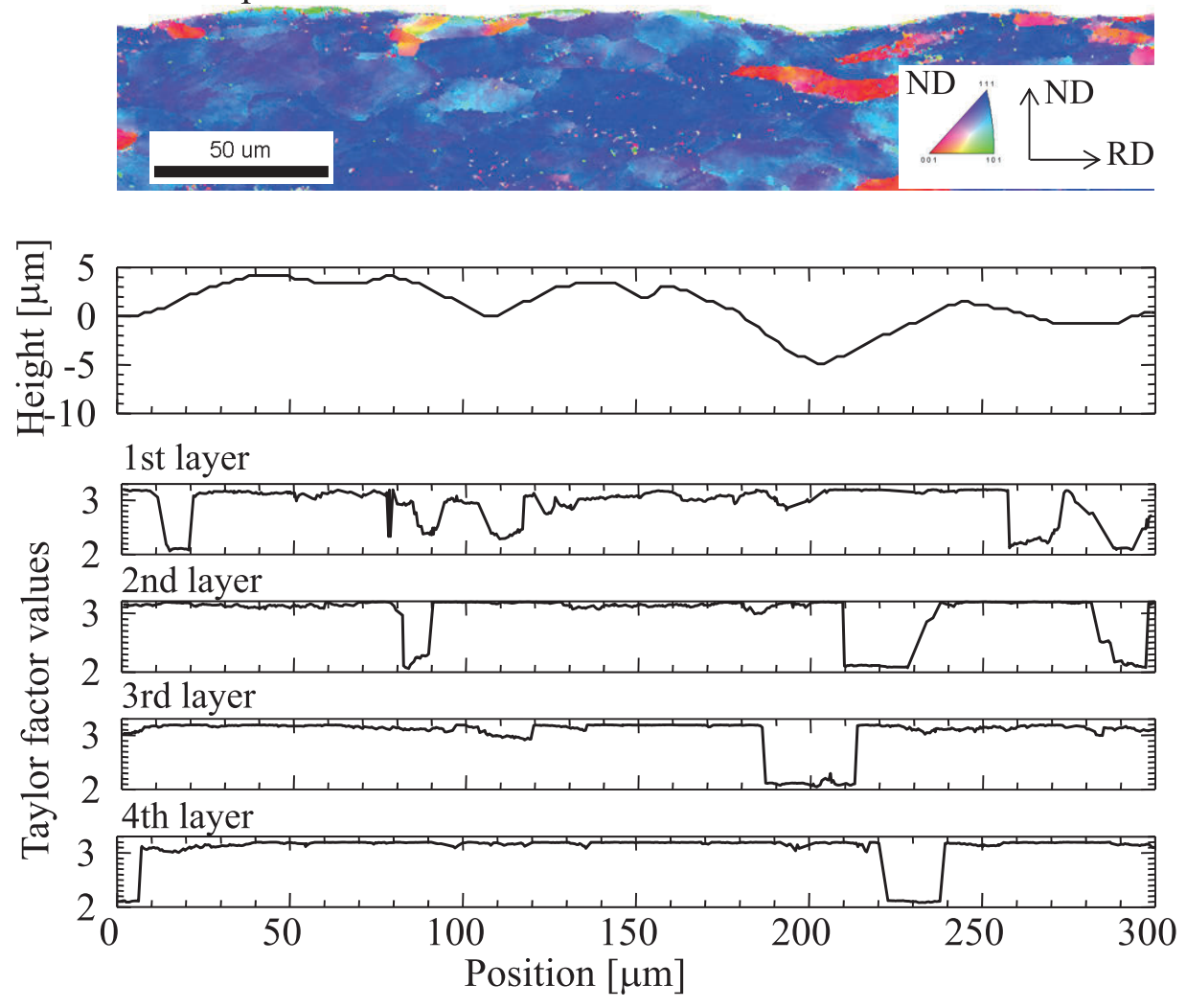

Fig. 13. IPF map, surface profile and Taylor factor of four layers from surface at ND-RD cross-section after Marciniak type test with equivalent strain of 0.50 for Material A. 


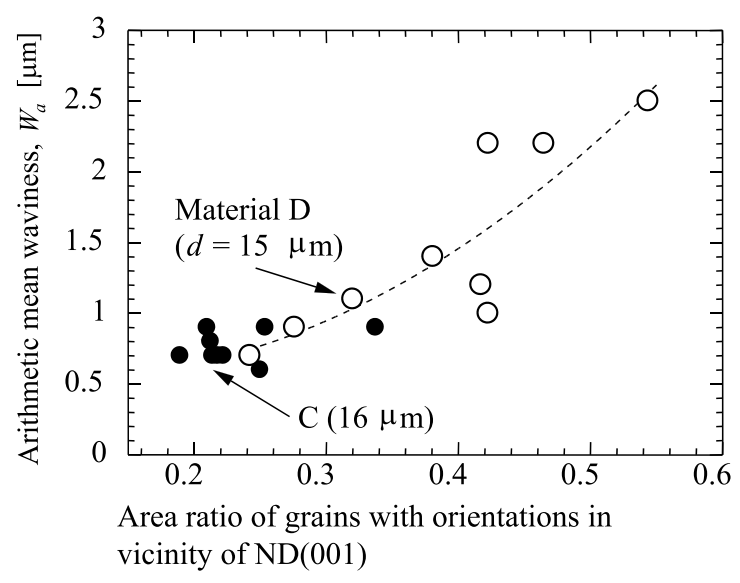

Fig. 14. Relation between surface waviness and area ratio of grains with orientations in vicinity of $\mathrm{ND}(001)$ at equivalent strain of 0.30 for Materials C and D.

grains have lower Taylor factors. At this position the concave is obviously seen in the surface profile. There is little difference in deformation resistance for the first layer in Fig. 13. It is considered that the interior crystal grains with $\mathrm{ND}(001)$ orientation may have a greater effect on the surface roughening in such a case.

Finally, in order to evaluate the effect of ND(001) orientation on surface roughening, the arithmetical mean waviness $W_{a}$ and the area of grains with orientations in the vicinity of $\mathrm{ND}(001)$ at the surface layer were measured for the specimens after Marciniak type tests with the equivalent strain of 0.3 at various cross sections with a length of 1.0 $\mathrm{mm}$. Figure 14 shows the relation between the area ratio of grains in the orientations within $15^{\circ}$ from $\mathrm{ND}(001)$ and $W_{a}$ for materials $\mathrm{C}$ and $\mathrm{D}$ with almost the same initial grain sizes. $W_{a}$ increases with the area ratio of grains with orientations in the vicinity of $\mathrm{ND}(001)$. It is verified that the surface roughening becomes large for the sheet which has a larger number of the crystal grains with orientations in the vicinity of $\mathrm{ND}(001)$ due to inhomogeneous deformation derived from their lower deformation resistance.

\section{Conclusion}

For the purpose of overcoming surface defects in press forming of steel sheets, the effects of texture and microstructure on surface roughening were investigated in this study. Marciniak type macroscopic biaxial tensile tests and microscopic tests in a vacuum chamber developed by the authors were carried out for three types of IF steel sheets and a common steel sheet, with various grain sizes and textures, and changes in surface profile and microstructure were observed in detail. The results obtained are summarized as follows.

(1) Not only the grain size but also the microstructure of the sheet has a large influence on surface roughening in biaxial tensile deformation.

(2) Good correspondence exists between the crystal grains with orientations in the vicinity of $\mathrm{ND}(001)$ and the concave parts of the surface after biaxial tensile deformation. This is considered to be due to the low deformation resistance of the crystal grains with these orientations.

(3) Surface roughening becomes larger for a sheet which has a larger number of crystal grains with orientations in the vicinity of $\mathrm{ND}(001)$ due to inhomogeneous deformation derived from their lower deformation resistance.

\section{REFERENCES}

1) Handbook on Press Forming, 3rd ed., ed. by Japan Deep Drawing Research Group, Nikkan Kogyo Shimbun, Tokyo, (2007), 94.

2) W. Tong: Technical Report Department of Mechanical Engineering, Yale University, New Haven, CT, (1997), 1.

3) K. Yamaguchi and P. B. Mellor: Int. J. Mech. Sci., 18 (1976), 85.

4) A. K. Tadros and P. B. Mellor: Int. J. Mech. Sci., 20 (1978), 121.

5) P. F. Thomson and P. U. Nayak: Int. J. Mach. Tool Des. Res., 20 (1980), 73.

6) K. Yamaguchi, N. Takakura and S. Imatani: J. Mater. Process. Technol., 48 (1995), 27.

7) R. Mahmudi and M. Mehdizadeh: J. Mater. Process. Technol., 80 (1998), 707.

8) Y. Z. Dai and F. P. Chiang: Trans. ASME, 114 (1992), 432.

9) D. V. Wilson, W. T. Roberts and P. M. B. Rodriguez: Metall. Trans. $A, \mathbf{1 2 A}(1981), 1603$.

10) K. Osakada and M. Oyane: Bull. JSME, 14 (1971), No. 68, 171.

11) A. Azushima and M. Miyagawa: J. Jpn. Soc. Technol. Plast., 27 (1986), 1261.

12) T. Kobayashi, K. Murata and H. Ishigaki: J. Jpn. Soc. Technol. Plast., 10 (1969), 793.

13) T. Kobayashi, K. Murata, H. Ishigaki and T. Abe: J. Jpn. Soc. Technol. Plast., 11 (1970), 495.

14) H. Ishigaki: Toyota Eng., 25 (1975), 64.

15) C. Guangnan, S. Huan, H. Shiguang and B. Baudelet: Mater. Sci. Eng. $A, \mathbf{A 1 2 8}$ (1990), 33.

16) J. H. Dautzenberg and J. A. G. Kals: Advanced Technology of Plasticity 1984, Vol. 1, Japan Society for Technology of Plasticity/Japan Society of Precision Engineering, Tokyo, (1984), 186.

17) P. A. Sundaram: Scr. Metall. Mater., 33 (1995), 1093.

18) N. Kawai, T. Nakamura and Y. Ukai: Bull. JSME, 51 (1985), 2100.

19) K. Yamaguchi, N. Takakura and M. Fukuda: JSME Int. J., 30 (1987), 2034.

20) A. J. Beaudoin, J. D. Bryant and D. A. Korzekwa: Metall. Mater. Trans. A, 29A (1998), 2323.

21) M. R. Stoudt and J. B. Hubbard: Acta Mater., 53 (2005), 4293.

22) T. J. Turner and M. P. Miller: J. Eng. Mater. Technol., 129 (2007), 367.

23) M. Fukuda, K. Yamaguchi, N. Takakura and Y. Sakano: J. Jpn. Soc. Technol. Plast., 15 (1974), 994.

24) F. Kanzaki and Y. Ito: Tetsu-to-Hagané, 51 (1965), 2142.

25) R. Becker: Acta Mater., 46 (1998), 1385.

26) W. Tong, L. G. Hector, Jr., H. Weiland and L. F. Wieserman: Scr. Mater., 36 (1997), 1339.

27) P. D. Wu, D. J. Lloyd, A. Bosland, J. Jin and S. R. MacEwen: Acta Mater., 51 (2003), 1945.

28) P. D. Wu and D. J. Lloyd: Acta Mater., 52 (2004), 1785.

$29)$ P. D. Wu, D. J. Lloyd, M. Jain, K. W. Neals and Y. Huang: Int. J. Plast., 23 (2007), 1084.

30) K. Kimura, S. Hirose, K. Ushioda, M. Hatano and A. Takahashi: $J$. Jpn. Inst. Met. Mater., 77 (2013), 440.

31) P. S. Lee, H. R. Piehler, B. L. Adams, G. Jarvis, H. Hampel and A. D. Rollett: J. Mater. Process. Technol., 80 (1998), 315.

32) S. W. Banovic and T. Foecke: Metall. Mater. Trans. A, 34A (2003), 657.

33) Y. Shi, P. Z. Zhao, H. Jin, P. D. Wu and D. J. Lloyd: Metall. Mater. Trans. A, 47A (2016), 949.

34) Z. Marciniak and K. Kuczynski: Int. J. Mech. Sci., 9 (1967), 609.

35) M. Kubo, H. Yoshida, A. Uenishi, S. Suzuki, Y. Nakazawa, T. Hama and H. Takuda: ISIJ Int., 56 (2016), 669.

36) ISO 4288: 1996, Geometrical Product Specifications (GPS) - Surface texture: Profile method - Rules and procedures for the assessment of surface texture.

37) ISO 1302: 2002, Geometrical Product Specifications (GPS) - Indication of surface texture in technical product documentation.

38) T. Kuroda and H. Kondo: Seimitsu Kikai, 22 (1956), 54.

39) M. Kubo, Y. Nakazawa, H. Yoshida, S. Yonemura, T. Hama and H. Takuda: ISIJ Int., 56 (2016), 2259.

40) G. I. Taylor: J. Inst. Met., 62 (1938), 307.

41) TSL solutions: OIM analysis version 7.2.1 technical reference, AMETEK, Inc., Berwyn, (2015).

42) J. Jiang, T. B. Britton and A. J. Wilkinson: Int. J. Plast., 69 (2015), 102.

43) I. Shimizu, H. Terai, T. Nosho and T. Abe: Bull. JSME, 64 (1998), 1043. 